\title{
Aliran Daya Optimal dengan Efek Katup Menggunakan Grey Wolf Optimization
}

\author{
Monica Amelia Oktaviani, Rony Seto Wibowo, dan Ni Ketut Aryani \\ Departemen Teknik Elektro, Fakultas Teknik Elektro \\ Institut Teknologi Sepuluh Nopember (ITS) 60111 Indonesia \\ e-mail: ronyseto@ee.its.ac.id
}

\begin{abstract}
Abstrak-Aliran daya optimal merupakan sebuah analisis yang bertujuan untuk meminimalkan biaya operasi dalam suatu sistem dimana daya yang dihasilkaan adalah daya optimal dengan memperhatikan segala batasan. Pemecahan masalah aliran daya optimal dapat menggunakan metode optimisasi matematika yang disebut juga metode kecerdasan buatan. Pada jurnal ini akan dibahas mengenai pemecahan masalah aliran daya optimal dengan efek katup menggunakan metode Grey Wolf Optimization. Implementasi dari metode Grey Wolf Optimization (GWO) ialah untuk mendapatkan nilai keluaran daya yang optimal dari masing-masing unit pembangkit yang diarahkan untuk mengecilkan fungsi objektif (harga). Sistem IEEE 9 bus dan sistem IEEE 30 bus dijadikan sebagai data unit pembangkit untuk menguji kemampuan metode GWO. Pada akhir jurnal akan dipaparkan perbandingan hasil simulasi akan pengaruh efek katup dengan metode GWO serta perbandingan biaya bahan bakar antara metode GWO dan metode yang telah dilakukan sebelumnya.
\end{abstract}

Kata Kunci-Aliran Daya Optimal, Efek Valve Point, Grey Wolf Optimization.

\section{PENDAHULUAN}

S ISTEM tenaga listrik merupakan salah satu alat dalam hal konversi energi dari satu bentuk ke bentuk lainnya dengan memperhatikan dampak dari masalah pencemaran lingkungan. Sistem tenaga listrik terdiri dari tiga bagian utama yaitu sistem pembangkit, sistem transmisi dan sistem distribusi, Sistem pembangkit merupakan suatu sistem yang berguna untuk membangkitkan tenaga listrik dari berbagai macam sumber energi[1]. Dalam pengoperasian, tiap unit pembangkit memiliki kurva biaya. Kurva biaya terbagi menjadi dua jenis yaitu kurva biaya tidak mulus dan kurva biaya mulus. Kurva biaya tidak mulus disebabkan oleh adanya koefisien akibat efek katup yang berakibat biaya operasi suatu sistem pembangkit menjadi mahal. Aliran daya optimal adalah salah satu analisis pada sistem pembangkit yang bertujuan untuk meminimalkan biaya operasi suatu pembangkit dengan menghasilkan daya output maksimal dalam segala batasan.

Pada artikel[2], [3], perhitungan Economic Dispatch menjadi langkah awal dalam analisis aliran daya optimal. Economic Dispatch adalah penjadwalan unit-unit pembangkit secara ekonomis pada suatu sistem sesuai permintaan. Tujuan utama dari Economic Dispatch adalah untuk menurunkan biaya operasi dari sistem pembangkit, ketika memasok permintaan daya yang sesuai. Metode konvensional yang digunakan untuk menyelesaikan Economic Dispatch yaitu metode linear programming, metode gradient, metode lambda iteration dan metode Newton.

Aliran daya optimal adalah pengembangan dari penyelesaian masalah Economic Dispatch pada suatu sistem tenaga listrik[4]. Penyelesaian analisis aliran daya optimal diklasifikasikan menjadi 2 jenis yaitu: metode konvensional dan metode heuristik. Metode heuristik atau yang sering disebut dengan metode optimisasi matematika dikembangkan dari metode konvensional karena adanya beberapa batasan yang tidak dapat diatasi selama proses meminimalisir biaya[5]. Grey Wolf Optimization merupakan metode metaheuristik yang terinspirasi dari perilaku dan mekanisme pemburuan oleh serigala abu-abu[6].

Pemaparan akhir pada jurnal ini yaitu penyelesaian aliran daya optimal akibat efek katup dengan menggunakan metode GWO. Pengujian metode GWO dilakukan pada sistem IEEE 9 Bus dan sistem IEEE 30 Bus. Pengaruh efek katup dijadikan sebagai pembanding batasan-batasan yaitu batasan tegangan, kapasitas saluran, dan aliran daya. Biaya bahan bakar juga menjadi subjek utama dalam perbandingan metode GWO dengan metode yang telah digunakan yatiu metode MHBMO.

\section{TINJAUAN PUSTAKA}

\section{A. Aliran Daya Optimal}

Salah satu masalah optimasi dalam rekayasa sistem tenaga listrik biasa atau yang sering dikenal dengan aliran daya optimal adalah salah satu sub bidang dari optimasi non linear terbatas yang paling penting dan telah banyak diteliti oleh para ilmuwan. Carpentier (1962) mengenalkan aliran daya optimal sebagai lanjutan masalah Economic Dispatch dari pembangkit suatu sistem tenaga listrik. Aliran daya optimal menyertakan berbagai masalah optimasi yang berusaha mengoptimalkan pengoperasian sistem tenaga listrik pada konstrain fisik berdasarkan hukum-hukum listrik dan batasan-batasan listrik. Persamaan matematika dalam penyelesaian aliran daya optimal adalah sebagai berikut:

Persamaan Economic Dispatch

$$
F\left(P_{g}\right)=\sum_{i=1}^{n}\left(a_{i} P_{g i}^{2}+b_{i} P_{g i}+c_{i}\right)
$$

mengacu pada batasan:

Konstrain keseimbangan daya

$$
\sum_{i=1}^{N} P_{i}=P_{d}+P_{L}
$$

Batasan kapasitas pembangkit

$$
P_{i \text { min }} \leq P_{i} \leq P_{i \max }
$$

Persamaan Aliran Daya Optimal

$$
P_{G a}-P_{D a}=V_{a} \sum_{n=1}^{N B} V_{b}\left(G_{a b} \cos \left(\theta_{a}-\theta_{b}\right)+B_{a b} \sin \left(\theta_{a}-\theta_{b}\right)\right)
$$




$$
Q_{G a}-Q_{D a}=V_{a} \sum_{n=1}^{N B} V_{b}\left(G_{a b} \sin \left(\theta_{a}-\theta_{b}\right)+B_{a b} \cos \left(\theta_{a}-\theta_{b}\right)\right)
$$

mengacu pada batasan:

\section{Batasan kapasitas pembangkit}

$$
\begin{aligned}
& P_{G i \text { min }} \leq P_{G i} \leq P_{G i \text {,max }} \\
& Q_{G i, \text { min }} \leq Q_{G i} \leq Q_{G i, \text { max }}
\end{aligned}
$$

\section{Batasan tegangan}

$$
V_{m, \text { min }} \leq V_{m} \leq V_{m, \text { max }}
$$

\section{Batasan saluran}

$$
S_{l} \leq S_{l, \max }
$$

Keterangan:

$F\left(P_{g}\right) \quad$ : total biaya pembangkitan

$a_{i}, b_{i}, c_{i}$ : koefisien biaya bahan bakar

$P_{d} \quad$ : beban daya

$P_{L} \quad$ : losses daya

$P_{G i} \quad$ : daya aktif yang dibangkitkan pada bus i

$Q_{G i} \quad$ : daya reaktif yang dibangkitkan pada bus i

$G_{a b}, B_{a b}$ : admitansi saluran a-b

$V_{a}, V_{b} \quad$ : tegangan bus a,b

$\theta_{a}, \theta_{b} \quad$ : sudut fasa tegangan bus a,b

\section{B. Akibat Efek katup}

Pada aliran daya optimal terdapat fungsi objektif yang didefinisikan sebagai total biaya bahan bakar termurah dari suatu sistem pembangkit. Efek katup adalah efek yang ada di kurva unit pembangkit ketika setiap katup uap yang masuk di turbin mulai terbuka. Unit pembangkit dengan katup uap dan turbin yang banyak akan menunjukkan beberapa variasi dari fungsi biaya bahan bakar. Rumus aliran daya optimal dengan efek katup adalah sebagai berikut:

$$
F_{i}\left(P_{G i}\right)=a_{i}+b_{i} P G_{i}+c_{i} P G_{i}^{2}+e_{i} \sin \left[f_{i}\left(P G_{i \min }-P G_{i}\right)\right]
$$

dimana $e_{i}, f_{i}$ adalah koefisien biaya bahan bakar akibat efek katup.

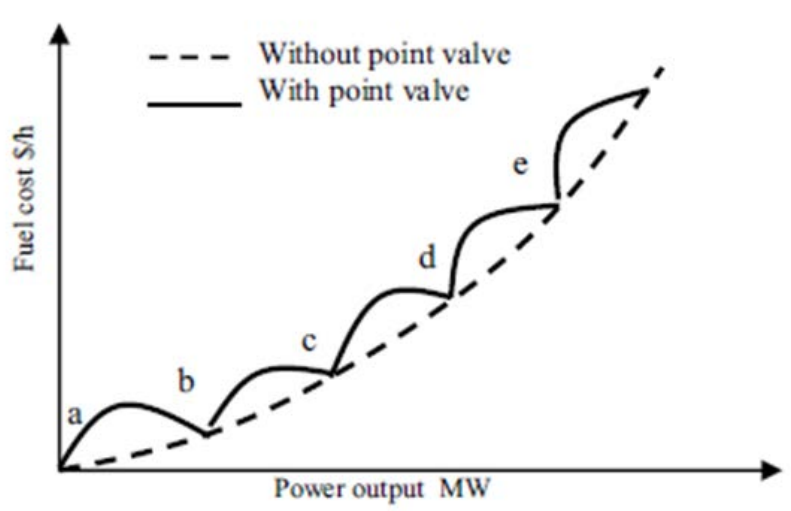

Gambar 1. Kurva biaya bahan bakar dengan daya output sistem

\section{Grey Wolf Optimization}

Serigala abu-abu (Grey Wolf) dikenal sebagai Apex Predator, artinya mereka berada di tingkat teratas dalam rantai makanan. Sebagian besar serigala abu-abu lebih memilih tinggal secara berkelompok. Dalam satu kelompok rata-rata terdapat 5-12 ekor. Algoritna ini terinspirasi oleh tingkah laku dan mekanisme pemburuan pada serigala abuabu.

Di dalam satu kelompok terdapat tingkatan sosial yaitu Alpha, Beta, Omega dan Delta.Tingkatan pertama yaitu
Alpha, bertugas untuk memimpin kelompok. Lalu diikuti oleh Beta yang mana adalah pemimpin kedua para serigala yang bertanggung jawab membantu alpha dalam mengambil keputusan. Beta memperkuat segala perintah alpha selama dalam kelompok dan memberikan tanggapan kepada alpha. Sedangkan, tingkatan terakhir pada kelompok serigala abuabu dikenal dengan omega yang seringkali menjadi kambing hitam. Mereka juga adalah serigala terakhir yang diijinkan untuk memakan mangsa. Jika serigala bukan pada tingkatan Alpha, Beta dan Omega, perannya dapat disebut dengan Delta. Peranan serigala Delta yaitu dapat sebagai pengintai, penjaga, tertua, pemburu dan pelindung.

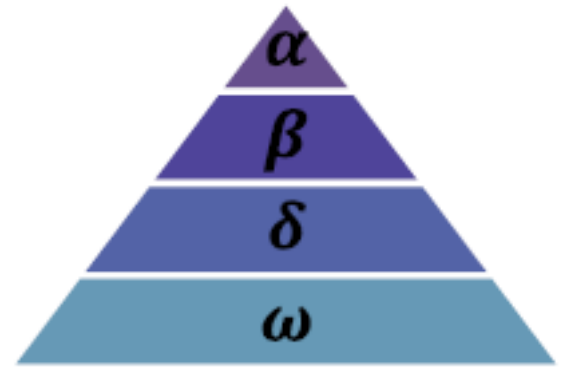

Gambar 2. Tingkatan Sosial Serigala Abu-Abu

Pada mekanisme pemburuan, para serigala akan mengitari mangsa terlebih dahulu. Hal ini berguna untuk menjaga agar mangsa tetap berada dalam area penyerangan. Permodelan matematika dalam tindakan mengitari mangsa sebagai berikut:

$$
\begin{aligned}
& \vec{D}=\left|\vec{c} \cdot \vec{X}_{p}(t)-\vec{X}(t)\right| \\
& \vec{X}(t+1)=\vec{X}_{p}(t)-\vec{A} \cdot \vec{D}
\end{aligned}
$$

Komponen t dijadikan sebagai iterasi terakhir, $\vec{A}$ dan $\vec{C}$ adalah koefisien vector, $\overrightarrow{X_{p}}$ adalah vektor posisi dari mangsa, dan $\vec{X}$ dijadikan sebagai vector posisi dari serigala abu-abu.

Vektor $\vec{A}$ dan $\vec{C}$ dihitung dengan ketentuan:

$$
\begin{aligned}
& \vec{A}=2 \vec{a} \cdot \vec{r}_{1}-\vec{a} \\
& \vec{C}=2 \cdot \vec{r}_{2}
\end{aligned}
$$

Dimana komponen dari $\vec{a}$ adalah turunan linier dari nilai 2 ke 0 selama iterasi berlangsung dan $r_{1}, r_{2}$ adalah random dari vektor $[0,1]$.

Serigala abu-abu memiliki kemampuan untuk mendeteksi lokasi dimana terdapat mangsa dan langsung mengitari mangsa tersebut. Secara umum, pemburuan dipimpin oleh serigala Alpha. Serigala Beta dan Delta mungkin juga berpartisipasi dalam pemburuan di waktu tertentu. Tugas dari serigala Alpha, Beta dan Delta adalah memperkirakan posisi dari mangsa, sedangkan serigala lainnya memperbarui posisi mereka secara acak tetapi tetap mengitari mangsa. alam permodelan matematika, perilaku serigala saat berburu dijadikan bahan simulasi. Berikut permodelan matematika dalam pemburuan:

$$
\begin{aligned}
& \vec{D}_{\alpha}=\left|\vec{C}_{1} \cdot \vec{X}_{\alpha}-\vec{X}\right| \\
& \vec{X}_{1}=\vec{X}_{\alpha}-\vec{A}_{1} \cdot\left(\vec{D}_{\alpha}\right) \\
& \vec{D}_{\beta}=\left|\vec{C}_{2} \cdot \vec{X}_{\beta}-\vec{X}\right| \\
& \vec{X}_{2}=\vec{X}_{\beta}-\vec{A}_{2} \cdot\left(\vec{D}_{\beta}\right)
\end{aligned}
$$




$$
\begin{aligned}
& \vec{D}_{\delta}=\left|\vec{C}_{3} \cdot \vec{X}_{\delta}-\vec{X}\right| \\
& \vec{X}_{3}=\vec{X}_{\delta}-\vec{A}_{3} \cdot\left(\vec{D}_{\delta}\right) \\
& \vec{X}(t+1)=\frac{\vec{X}_{1}+\vec{X}_{2}+\vec{X}_{3}}{3}
\end{aligned}
$$

Serigala abu-abu menyelesaikan pemburuannya dengan menyerang mangsa ketika mangsanya tidak lagi bergerak. Dalam permodelan matematika, pendekatan terhadap mangsa dilakukan dengan cara menurunkan nilai $\vec{a}$. Menjadi catatan bahwa jarak fluktuasi dari nilai $\vec{A}$ bergantung pada penurunan nilai $\vec{a}$. Nilai $\vec{A}$ adalah nilai acak dari interval [-2a,2a] dimana nilai a adalah penurunan dari nilai 2 hingga 0 untuk semua rangkaian iterasi.

Komponen lainnya dalam Grey Wolf Optimization (GWO) adalah nilai $\vec{C}$. Nilai vektor $\vec{C}$ berupa nilai random dari $[0,2]$. Komponen ini mengandung nilai random mangsa secara stokastik. Terdapat 2 keadaan yaitu keadaan tertekan $(\mathrm{C}>1)$ atau keadaan tidak tertekan $(\mathrm{C}<1)$ saat terjadi perburuan dimana jarak diperhitungkan. Hal tersebut dapat membantu GWO untuk menunjukkan perilaku random lainnya selama optimasi, membantu eksplorasi dan menghindari local optima. Nilai C tidak menurun secara linear seperti nilai A. Nilai ini sangat membantu local optima stagnation, terutama pada iterasi terakhir. Vektor C juga dapat dijadikan sebagai efek dari penghambat dalam mendekati mangsa di alam liar.

\section{ALIRAN DAYA OPTIMAL DENGAN METODE GREY WOLF OPTIMIZATION}

Penyelesaian masalah aliran daya optimal dengan metode Grey Wolf Optimization memiliki tujuan untuk mendapatkan biaya operasi suatu unit pembangkit yang paling murah. Berikut adalah penjelasan alur penyelesaian aliran daya optimal menggunakan metode Grey Wolf Optimization berdasarkan gambar 2 .

1. Inisialisasi data-data yang dibutuhkan seperti jumlah populasi, jumlah iterasi maksimal, banyaknya generator, parameter nilai Alpha, Beta dan Delta, dan posisi serigala. Inisialisasi nilai Alpha, Beta dan Delta berdasarkan tingkatan sosial pada serigala. Inisialisasi posisi serigala berdasarkan nilai daya (P) secara acak pada tiap pembangkit.

2. Pengecekkan posisi serigala berdasarkan batasan-batasan yang harus dipenuhi pada persamaan Economic Dispatch dan aliran daya optimal.

3. Pembaharuan nilai Alpha, Beta dan Delta sesuai dengan hasil dari proses pengecekkan posisi serigala. Pembaharuan akan dilakukan sesuai banyaknya iterasi. Hasil akhir adalah Alpha membawa hasil terbaik pertama, Beta membawa hasil terbaik kedua, dan Delta membawa hasil terbaik ketiga.

4. Perhitungan fitness berdasarkan proses mengitari musuh dan berburu. Pada proses mengitari musuh, pembaharuan nilai Alpha, Beta dan Delta akan dicek apakah tetap berada dalam range algoritma GWO. Proses berburu digunakan untuk memperbaharui posisi serigala hingga iterasi terakhir.

5. Penentuan solusi terbaik berdasarkan Alpha, Beta dan Delta.

6. Perhitungan fungsi objektif berupa Economic Dispatch dan aliran daya optimal.

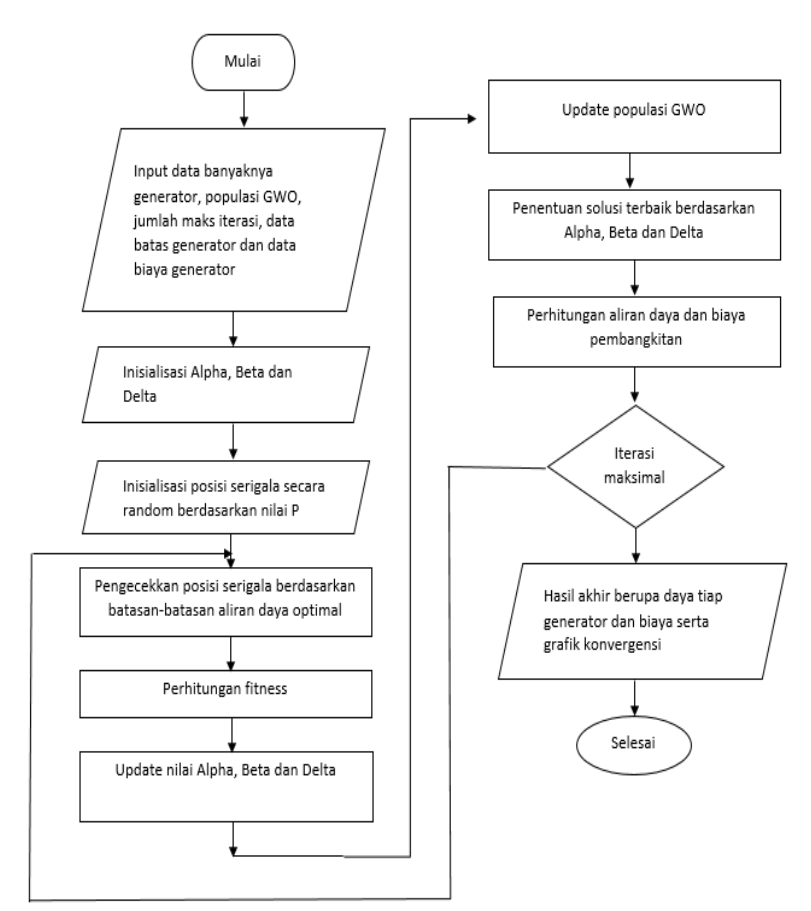

Gambar 3. Diagram Alur Aliran Daya Optimal dengan Grey Wolf Optimization

\section{SIMULASI DAN ANALISIS}

Pengujian metode GWO pada analisis aliran daya optimal dengan efek katup menggunakan 2 buah sistem yaitu sistem IEEE 9 Bus dan 30 Bus. Dengan menggunakan kurva biaya tidak mulus (non smoothing), didapatkan hasil dari batasanbatasan aliran daya optimal pengaruh efek katup pada tiap unit pembangkitan dan perbandingan total biaya pembangkitan dengan metode yang telah dilakukan yaitu MHBMO.

\section{A. Sistem IEEE 9 Bus}

Sistem transmisi IEEE 9 Bus terdiri dari 9 bus, 3 generator dan 9 saluran. Inisialisasi populasi pada GWO sebesar 300 dan maksimal iterasi sebesar 200. Pada simulasi pertama, dilakukan pengujian nilai tegangan akibat efek katup dan tanpa efek katup. Batasan tegangan ditentukan antara $0.95 \mathrm{~V}$ dan 1.06 V. Dari hasil simulasi, didapatkan bahwa nilai tegangan tidak melampaui batas yang ditentukan baik akibat efek katup ataupun tidak.

Selanjutnya, simulasi kedua adalah pengujian efek katup pada kapasitas daya tiap saluran. Batasan kapasitas daya ditentukan berdasarkan saluran masing-masing. Dan didapatkan hasil bahwa nilai daya pada tiap saluran tidak ada yang melampaui batas baik akibat efek katup atau tidak.

Simulasi ketiga yaitu perbandingan daya tiap unit pembangkit. Batasan daya minimal dan batasan daya maksimal ditentukan berdasarkan unit pembangkit. Daya yang dibangkitkan tiap unit pembangkit tidak ada yang melampaui batasan daya baik akibat efek katup dan tanpa efek katup.

Simulasi terakhir adalah melakukan perbandingan total biaya pembangkitan antara metode GWO dan metode MHBMO. Untuk total biaya pembangkitan akibat efek katup pada metode GWO sebesar 5491,226 \$/hr. Sedangkan pada metode MHBMO sebesar 5494,6866 \$/hr. Untuk total biaya pembangkitan tanpa efek katup pada metode GWO sebesar 5314,7752 \$/hr dan pada metode MHBMO sebesar 5316,04 $\$ / \mathrm{hr}$. 


\section{B. Sistem IEEE 30 Bus}

Sistem transmisi IEEE 30 Bus terdiri dari 30 bus, 6 generator dan 41 saluran. Pada simulasi pertama, menguji nilai tegangan terhadap pengaruh efek katup. Diberikan batasan nilai tegangan antara $0.9 \mathrm{~V}$ dan $1.06 \mathrm{~V}$. Hasil yang didapatkan yaitu tidak ada nilai tegangan yang melampaui batasan yang ditentukan. Berikut hasil pengujian nilai tegangan.

Tabel 1.

Perbandingan nilai tegangan

\begin{tabular}{|c|c|c|}
\hline Bus No & Akibat Efek Katup (V) & Tanpa Efek Katup (V) \\
\hline 1 & 1,06 & 1,06 \\
\hline 2 & 1,043 & 1,043 \\
\hline 3 & 1,026 & 1,026 \\
\hline 4 & 1,018 & 1,018 \\
\hline 5 & 1,01 & 1,01 \\
\hline 6 & 1,011 & 1,011 \\
\hline 7 & 1,002 & 1,002 \\
\hline 8 & 1,01 & 1,01 \\
\hline 9 & 1,01 & 1,01 \\
\hline 10 & 0,988 & 0,988 \\
\hline 11 & 1,052 & 1,052 \\
\hline 12 & 1,009 & 1,009 \\
\hline 13 & 1,041 & 1,041 \\
\hline 14 & 0,992 & 0,992 \\
\hline 15 & 0,986 & 0,986 \\
\hline 16 & 0,992 & 0,992 \\
\hline 17 & 0,984 & 0,984 \\
\hline 18 & 0,974 & 0,974 \\
\hline 19 & 0,97 & 0,97 \\
\hline 20 & 0,974 & 0,974 \\
\hline 21 & 0,975 & 0,975 \\
\hline 22 & 0,975 & 0,975 \\
\hline 23 & 0,972 & 0,972 \\
\hline 24 & 0,962 & 0,962 \\
\hline 25 & 0,966 & 0,966 \\
\hline 26 & 0,947 & 0,947 \\
\hline 27 & 0,977 & 0,977 \\
\hline 28 & 1,006 & 1,006 \\
\hline 29 & 0,956 & 0,956 \\
\hline 30 & 0,944 & 0,944 \\
\hline
\end{tabular}

Pada simulasi kedua, menguji pengaruh efek katup terhadap kapasitas daya tiap saluran. Batasan kapasitas daya ditentukan sesuai dengan tiap saluran. Hasil yang didapatkan yaitu bahwa kapasitas daya dengan metode GWO tidak ada yang melampaui batasan yang ditentukan pada tiap saluran. Berikut hasil pengujian kapasitas daya dengan metode GWO.

Tabel 2.

Perbandingan nilai kapasitas daya

\begin{tabular}{ccccc}
\hline \hline $\begin{array}{c}\text { Bus } \\
\text { Dari }\end{array}$ & Ke & $\begin{array}{c}\text { Tanpa Efek } \\
\text { Katup (MVA) }\end{array}$ & $\begin{array}{c}\text { Akibat Efek } \\
\text { Katup (MVA) }\end{array}$ & $\begin{array}{c}\text { Kapasitas } \\
\text { Saluran (MVA) }\end{array}$ \\
\hline 1 & 2 & 79,085 & 75,078 & 130 \\
1 & 3 & 55,327 & 54,125 & 130 \\
2 & 4 & 36,759 & 36,682 & 65 \\
3 & 4 & 51,559 & 50,425 & 130 \\
2 & 5 & 51,149 & 49,099 & 130 \\
2 & 6 & 47,327 & 46,979 & 65
\end{tabular}

\begin{tabular}{|c|c|c|c|c|}
\hline 4 & 6 & 46,764 & 45,632 & 90 \\
\hline 5 & 7 & 5,16 & 5,469 & 70 \\
\hline 6 & 7 & 21,14 & 19,672 & 130 \\
\hline 6 & 8 & 21,317 & 21,311 & 60 \\
\hline 6 & 9 & 20,214 & 20,254 & 65 \\
\hline 6 & 10 & 14,139 & 14,161 & 32 \\
\hline 9 & 11 & 22,707 & 22,699 & 65 \\
\hline 9 & 10 & 36,462 & 36,49 & 65 \\
\hline 4 & 12 & 32,978 & 32,93 & 65 \\
\hline 12 & 13 & 25,612 & 25,607 & 65 \\
\hline 12 & 14 & 8,533 & 8,527 & 32 \\
\hline 12 & 15 & 20,184 & 20,158 & 32 \\
\hline 12 & 16 & 8,97 & 8,945 & 32 \\
\hline 14 & 15 & 2,067 & 2,063 & 16 \\
\hline 16 & 17 & 4,95 & 4,928 & 30 \\
\hline 15 & 18 & 6,649 & 6,634 & 16 \\
\hline 18 & 19 & 3,279 & 3,265 & 32 \\
\hline 19 & 20 & 6,87 & 6,887 & 40 \\
\hline 10 & 20 & 9,339 & 9,355 & 32 \\
\hline 10 & 17 & 5,916 & 5,945 & 32 \\
\hline 10 & 21 & 18,932 & 18,935 & 32 \\
\hline 10 & 22 & 9,049 & 9,051 & 32 \\
\hline 21 & 22 & 2,102 & 2,099 & 32 \\
\hline 15 & 23 & 6,853 & 6,842 & 16 \\
\hline 22 & 24 & 6,829 & 6,835 & 16 \\
\hline 23 & 24 & 3,361 & 3,355 & 16 \\
\hline 24 & 25 & 1,09 & 1,097 & 16 \\
\hline 25 & 26 & 4,271 & 4,271 & 16 \\
\hline 25 & 27 & 5,365 & 5,372 & 16 \\
\hline 28 & 27 & 19,485 & 19,495 & 65 \\
\hline 27 & 29 & 6,43 & 6,43 & 16 \\
\hline 27 & 30 & 7,307 & 7,307 & 16 \\
\hline 29 & 30 & 3,758 & 3,758 & 16 \\
\hline 8 & 28 & 0,876 & 0,881 & 45 \\
\hline 6 & 28 & 17,29 & 17,301 & 32 \\
\hline
\end{tabular}

Pada simulasi ketiga, menguji pengaruh efek katup pada besar daya yang dibangkitkan pada tiap unit pembangkit. Terdapat batasan daya berupa daya minimum dan daya maksimal. Hasil yang didapatkan adalah bahwa dengan metode GWO, nilai daya yang dibangkitkan tiap unit pembangkit tidak ada yang melampaui batasan daya yang ditentukan baik akibat efek katup atau tanpa efek katup. Berikut ini hasil dari pengujian daya yang dibangkitkan tiap unit pembangkit.

Pada simulasi keempat, melakukan perbandingan biaya pembangkitan tiap unit pembangkit baik akibat efek katup atau tanpa efek katup antara metode GWO dan metode MHBMO. Pengaruh akibat efek katup menyebabkan biaya pembangkitan lebih mahal dibandingkan tanpa efek katup. Hal ini disebabkan karena adanya koefisien e dan f yang merupakan koefisien biaya bahan bakar. Berikut hasil dari perbandingan biaya pembangkitan tiap unit pembangkit. Total biaya pembangkitan yang dihasilkan menggunakan metode GWO lebih murah dibandingkan metode MHBMO. Pada saat adanya tanpa efek katup, dengan metode GWO, total biaya pembangkitan sebesar 546,4525 \$/hr. Sedangkan dengan metode MHBO adalah sebesar 780,2877 \$/hr. Berikut 
grafik perbandingan total biaya pembangkitan antara kedua metode tanpa efek katup.

Pada saat adanya efek katup, dengan metode GWO, total biaya pembangkitan sebesar 563,9168 \$/hr. Sedangkan dengan metode MHBMO, total biaya pembangkitan sebesar 803,0844 \$/hr. Berikut grafik perbandingan total biaya pembangkitan antara kedua metode akibat efek katup.

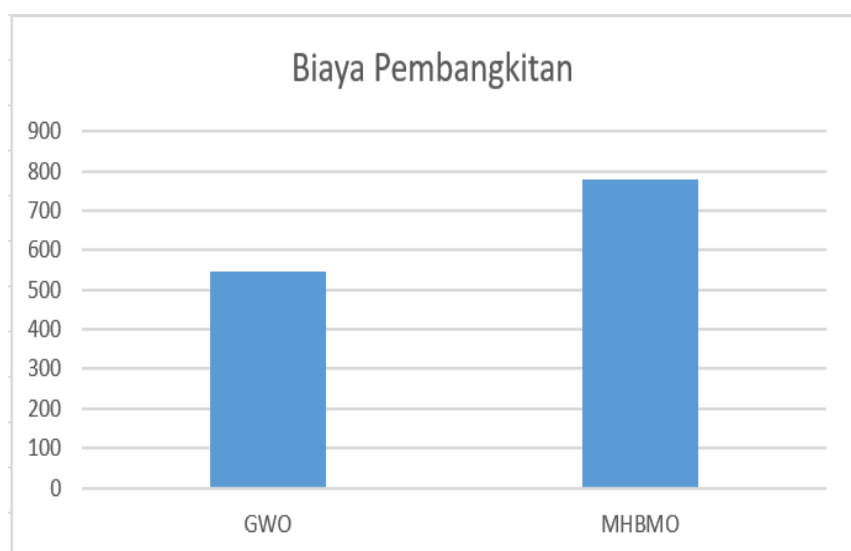

Gambar 4. Grafik perbandingan total biaya pembangkitan tanpa efek katup

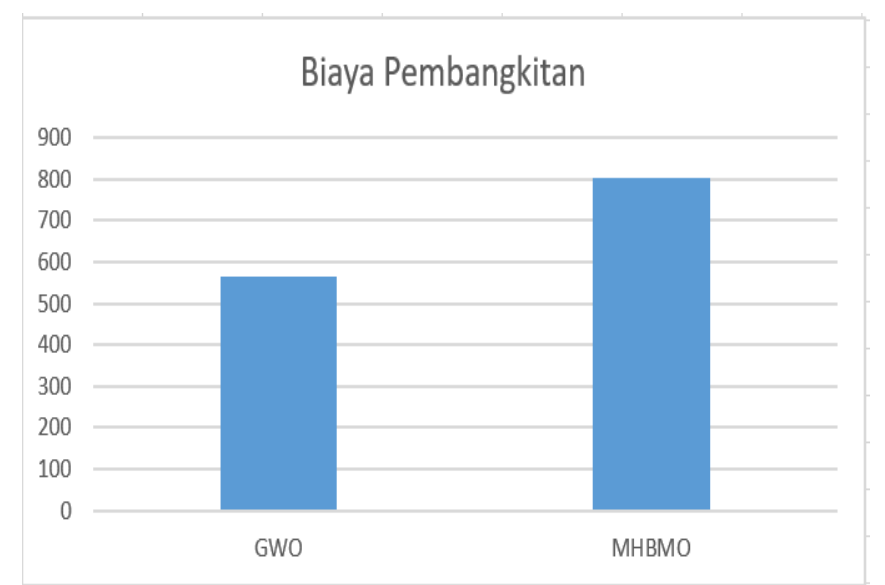

Gambar 5. Grafik perbandingan total biaya pembangkitan akibat efek katup.

Tabel 3.

Perbandingan nilai daya yang dibangkitkan

\begin{tabular}{ccccc}
\hline \hline Pembangkit & $\begin{array}{c}\text { Tanpa Efek } \\
\text { Katup (MW) }\end{array}$ & $\begin{array}{c}\text { Akibat Efek } \\
\text { Katup (MW) }\end{array}$ & $\begin{array}{c}\text { Pmin } \\
\text { (MW) }\end{array}$ & $\begin{array}{c}\text { Pmax } \\
\text { (MW) }\end{array}$ \\
\hline P1 & 128,9052 & 133,2258 & 50 & 250 \\
P2 & 80 & 79,3447 & 20 & 80 \\
P5 & 50 & 46,4089 & 15 & 50 \\
P8 & 10 & 10,0012 & 10 & 55 \\
$P 11$ & 10 & 10 & 10 & 30 \\
$P 13$ & 12 & 12 & 12 & 40 \\
\hline \hline
\end{tabular}

Tabel 4.

Perbandingan biaya pembangkitan tiap unit pembangkit

\begin{tabular}{ccccc}
\hline \hline \multirow{2}{*}{ Pembangkit } & \multicolumn{2}{c}{ Daya (MW) } & \multicolumn{2}{c}{ Biaya (\$/hr) } \\
\cline { 2 - 5 } & $\begin{array}{c}\text { Tanpa Efek } \\
\text { Katup }\end{array}$ & $\begin{array}{c}\text { Akibat Efek } \\
\text { Katup }\end{array}$ & $\begin{array}{c}\text { Tanpa Efek } \\
\text { Katup }\end{array}$ & $\begin{array}{c}\text { Akibat Efek } \\
\text { Katup }\end{array}$ \\
\hline P1 & 128,9052 & 133,2258 & 257,8142 & 267,5749 \\
P2 & 80 & 79,3447 & 140,0175 & 151,2685 \\
P5 & 50 & 46,4089 & 50,0625 & 46,5105 \\
P8 & 10 & 10,0012 & 32,5083 & 32,5128 \\
P11 & 10 & 10 & 30,025 & 30,025 \\
P13 & 12 & 12 & 36,025 & 36,025 \\
Total & 290,9052 & 290,9806 & 546,4525 & 563,9168 \\
\hline \hline
\end{tabular}

\section{KESIMPULAN/RINGKASAN}

1. Metode Grey Wolf Optimization dapat dijadikan sebagai solusi dalam penyelesaian permasalahan aliran daya optimal dengan mempertimbangkan pengaruh efek katup.

2. Pengaruh akibat efek katup ada pada besar daya yang dihasilkan dan biaya pembangkitan tiap unit pembangkit. Sebuah sitstem akan lebih mudah konvergen jika tanpa efek katup. Untuk biaya tiap unit pembangkit, akibat efek katup menyebabkan biaya pembangkitan lebih mahal dibandingkan tanpa efek katup.

3. Total biaya pembangkitan menggunakan metode GWO menghasilkan biaya yang lebih murah dibandingkan dengan menggunakan metode MHBMO baik saat adanya akibat efek katup dan tanpa efek katup.

\section{DAFTAR PUSTAKA}

[1] H. Saadat, Power system analysis. Boston: WCB/McGraw-Hill, 1999.

[2] M. Herwan Sulaiman, W. Lo Ing, Z. Mustaffa, and M. Rusllim Mohamed, "Grey wolf optimizer for solving economic dispatch problem with valve-loading effects,” ARPN J. Eng. Appl. Sci., vol. 10, no. 21, pp. 9796-9801, 2015.

[3] S. Sharma, S. Mehta, and N. Chopra, "Economic load dispatch using grey wolf optimization,” J. Eng. Res. Appl., vol. 5, no. 4, pp. 128132, 2015.

[4] S. Frank and S. Rebennack, "An introduction to optimal power flow: Theory, formulation, and examples,” IIE Trans., vol. 48, no. 12, pp. 1172-1197, Dec. 2016.

[5] B. E. Turkay and R. I. Cabadag, "Optimal power flow solution using particle swarm optimization algorithm,” in Eurocon 2013, 2013, pp. 1418-1424.

[6] S. Mirjalili, S. M. Mirjalili, and A. Lewis, "Grey Wolf Optimizer," Adv. Eng. Softw., vol. 69, pp. 46-61, Mar. 2014. 